\title{
The assessment of integration effects accounting the stochasticity of wind and solar power plants generation in the Asian Power Grid
}

\author{
Leonid Trofimov ${ }^{1}$, Ivan Trofimov ${ }^{1, *}$ \\ ${ }^{1}$ Melentiev Energy Systems Institute of Siberian Branch of the Russian Academy of Sciences, 664033 Irkutsk, Russia
}

\begin{abstract}
Electricity generation by wind and solar power plants (WPP and SPP) is characterized by the uncertainty of the time and generation volumes, and does not correlate with the demand determined by the graph of daily electric load. By using of the ORIRES optimization model, the integration effects associated with various scenarios of interstate power grid expansion are calculated. The stochastic generation of WPP and SPP creates a certain variation in the model solutions, but does not affect to the total integration effects. The article presents the calculations carried out on a large number of variations for wind and solar power generation. The stability (constancy) of total integration effects is shown, despite the stochastic generation of WPP and SPP in the considered energy power systems.
\end{abstract}

\section{Introduction}

To study different scenarios the Interstate Power Grid expansion (IPG) of the Northeast Asia \& Central Asia countries in the Melentiev Energy Systems Institute, the ORIRES optimization model is used (hereinafter - the Model). In this Model, a linear optimization method is used to find a solution, which determines the optimal installed capacity and generation type mix of the energy power systems (EPS) and their interconnections, the intersystem and interstate electric ties transfer capabilities, and the operating modes of these capacities and ties. Each EPS is represented in the Model by power demand characterized by a graph of daily electrical load, which determines how much electricity needs to generate for each hour. The problem of determining the actual power for each type of power plants is considered in the modeled EPSs, taking into account the electricity transfer between these systems. The main result is a solution, which takes into account the minimum annualized costs, computing the optimal structure of various capacity types in each EPS and their optimal operating modes at each hour of the day and in different seasons of the year (winter / spring / summer / fall, weekdays / weekends) [1-3].

The model takes into account the most common types of electricity generation by types of power plants Co-generation, hydro-power plants, nuclear, solar (SPP) and wind power plants (WPP). The WPP and SPP capacities give generation volumes unpredictable in time and power to the design scheme, which can lead to variations in the Model solution. In this paper, a quantitative assessment of these variations is carried out.

\section{Data representation features of wind and solar power plants capacities}

As an example, in Fig. 1 presents graphs and diagrams for the Northeast \& Central China energy power system (hereinafter - "NE\&C China EPS"), for the estimated 2035 target year, constructed by the Computing and Geo-Information System, developed by the authors [4-8].

On the left side of Fig. 1(a) the middle column shows the total optimized values obtained by the Model of new installed capacities by generation type mix. Some of constraints (max and min installed capacities) are shown at the columns to the left and to the right sides of the optimized values column.

On the right side of Fig. 1(b) shows the graph of daily electrical load (by hours) in the "NE\&C China" node. The diagrams below the daily load graph show the optimized contribution to the generation type mix (by different type of power plants). 


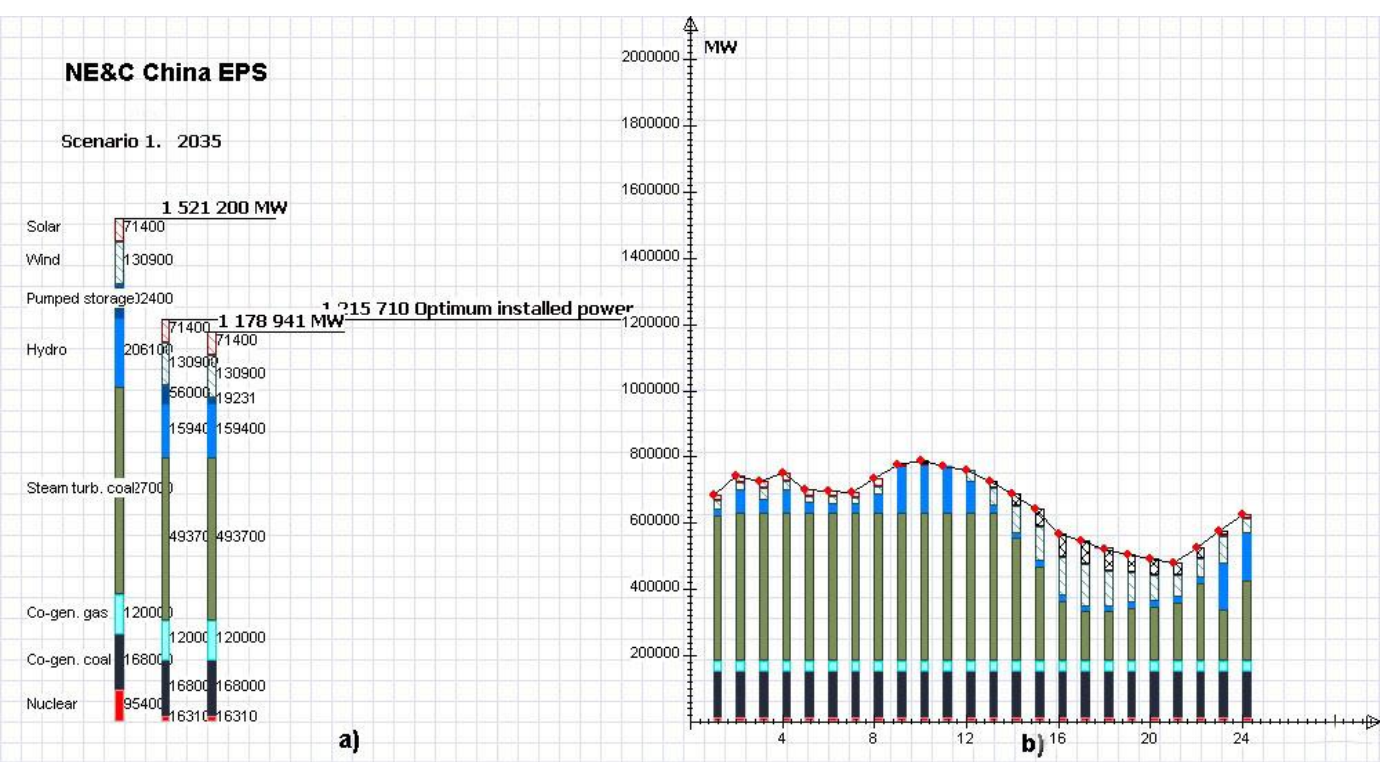

Fig. 1. a) Max, min and optimized installed capacities; b) The graph of daily electrical load "NE\&C China EPS", winter, weekday, 2035.

Daily load graphs vary depending on the season of the year (winter / spring / summer / autumn) and the type of day (weekday / holyday). For all graphs the optimal diagrams with the optimizing costs are constructed.

The generation of wind and solar power plants cannot be controlled by a human (system operator). Optimization of its contribution to covering the daily load graph does not make sense. In the Model, it is specified by some fixed set of values for each hour of daily generation, which are constants when solving the optimization problem. Only contributions to the generation of other types of power plants are optimized. Obviously, changes in the volumes of the hourly generation of WPP and SPP in the daily load graph can change (vary) the Model's solutions and, in particular, the value of the objective function.

The aim of this work is to assess the impact of variations in the contribution of WPP and SPP generation on the total solution of the optimization model. Installed capacities of WPP and SPP are not optimized, and are set (vary) to form various solutions of the model. Variations of the WPP and SPP contributions for "NE\&C China EPS", as the largest node in the design scheme, are considered below. The share of installed capacity of WPP and SPP in it is only $16-17 \%$ of the total optimized capacity.

\section{Comparison of scenarios of the IPG expansion}

Consider the results of the calculations of three scenarios of the Northeast and Central Asia countries in the 11node model for 2035. In Fig. 2, the main indicators of the solution of optimization problem for scenario 1 are plotted on the map (isolated operation of each EPS).

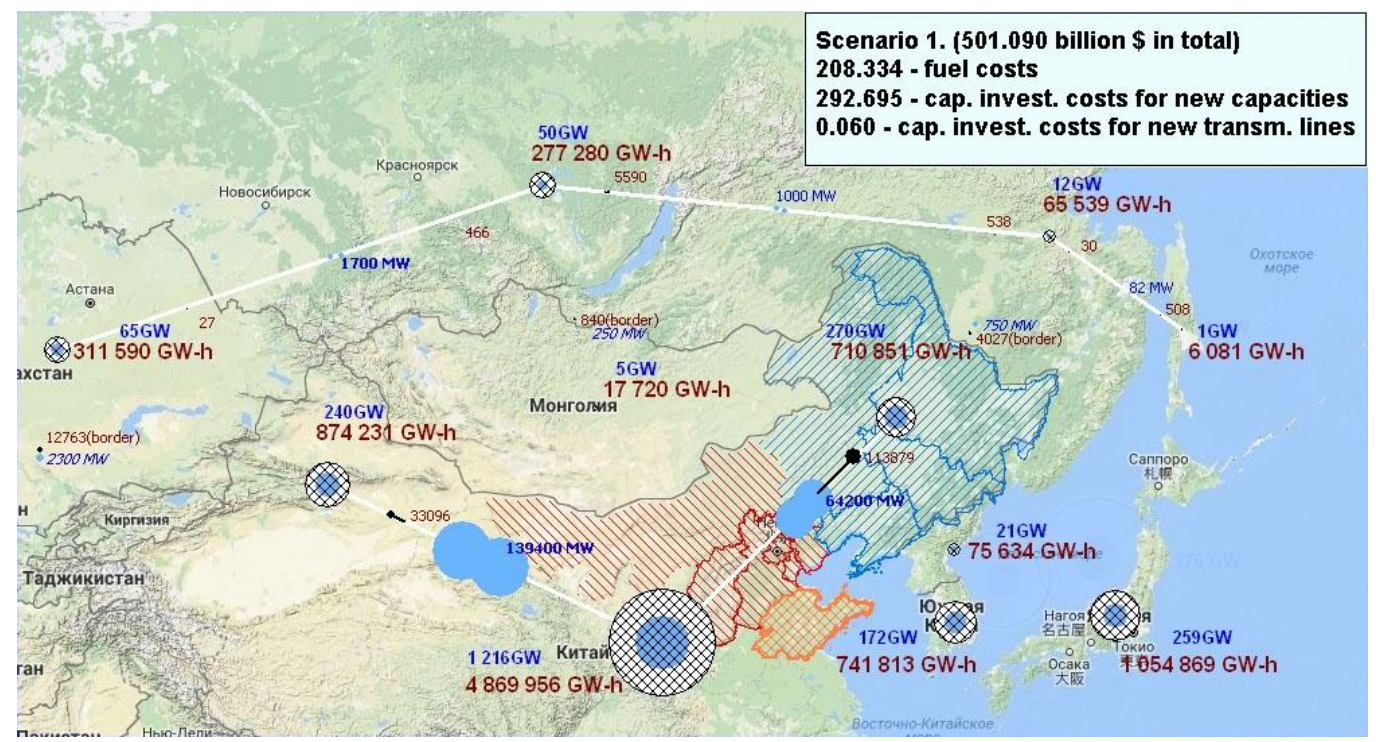

Fig. 2. The design scheme of Northeast Asia and Central Asia for 2035. Scenario 1, isolated operation. 


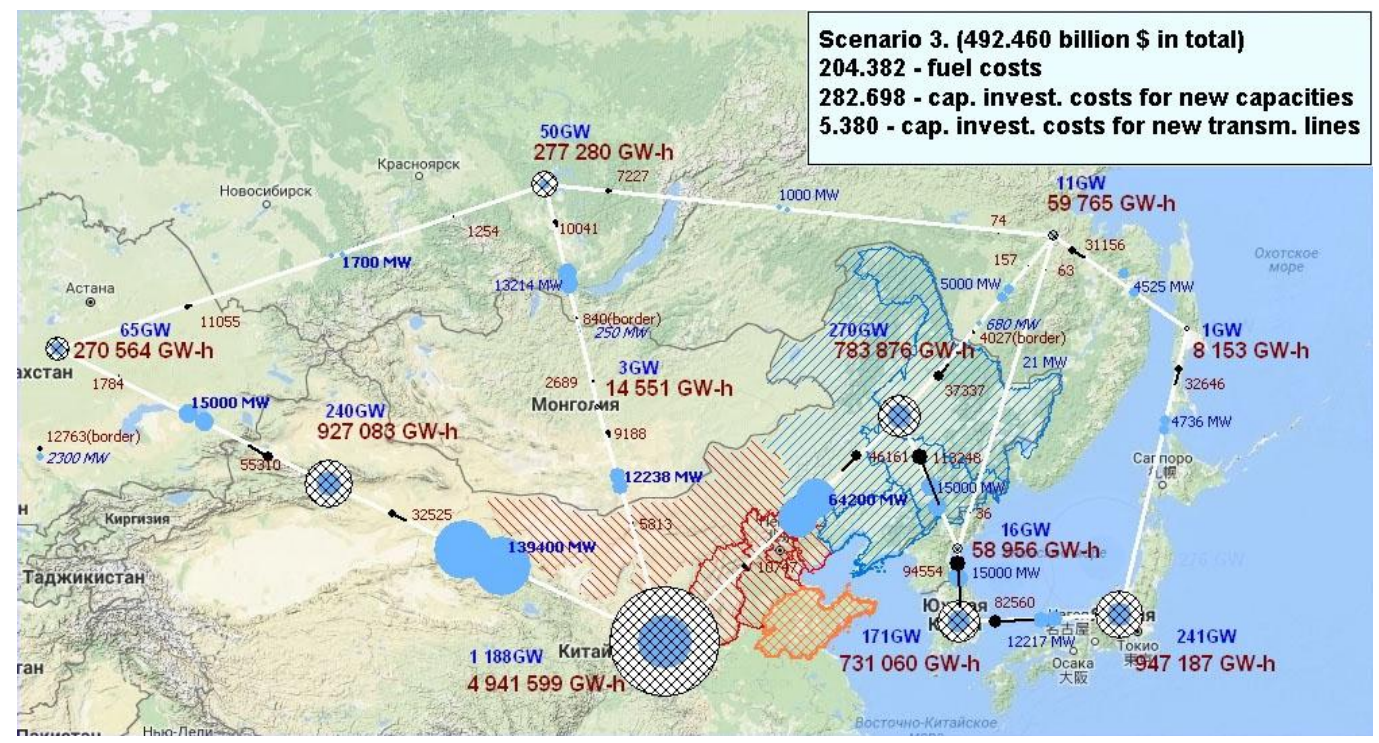

Fig. 3. The design scheme of Northeast Asia and Central Asia for 2035. Scenario 3, interconnected operation.

Some of the nodes on Fig. 2 are connected by electric ties, but only inside the countries. Near each node, there are values of indicators obtained by the Model solution. The total optimized installed capacities for each node (in $G W$ ), the total annual power generation in each node (in $G W h)$ are indicated. The connections indicate their transfer capabilities, and annual electricity flows. In the upper right corner of the map shows the total financial costs in billions of dollars, divided into three components: fuel costs, capital investments \& operating costs for new capacities and costs for new electric ties.

Fig. 3 shows the map with design scheme for scenario 3, which differs from scenario 1 by adding new interstate electric ties between all nodes. Comparing these two scenarios (isolated and interconnected operation) you can notice the less value of new installed capacities for all nodes in scenario 3 .

In addition, the total investment costs (the value of the objective function) are decreased, primarily due to investments in new installed capacities by generation type mix. Table 1 shows the total costs for three scenarios.

Table 1. The total investment costs, original variant.

\begin{tabular}{|l|l|}
\hline \multicolumn{1}{|c|}{ Scenarios } & Total costs, billion \$ \\
\hline Scenario 1, isolated operation & 501.089 \\
\hline $\begin{array}{l}\text { Scenario 2, interconnected } \\
\text { operation without Cenrtal } \\
\text { Asia }\end{array}$ & 493.535 \\
\hline $\begin{array}{l}\text { Scenario 3, Northeast Asia } \\
\text { and Central Asia } \\
\text { interconnected operation }\end{array}$ & 492.46 \\
\hline
\end{tabular}

In this table, there is solution for scenario 2, which differs from scenario 3 in "Central Asia EPS - Northwest China EPS" connection has not been included. The total costs in it, are slightly larger than in scenario 3. Thus, we can note the one of the integration effects [9] - the total costs decreasing in interconnected operation scenarios. It can be assumed that, due to the lack of installed capacities is compensated by the import of electricity from other connected nodes.

\section{Series of computational experiments with variations on the WPP contribution to total generation}

All calculations for the three scenarios from Table 1 were carried out with fixed WPP generation for "NE\&C China EPS". For each season: winter, spring, summer and autumn has its own graph. These four graphs are shown on the Fig. 4.

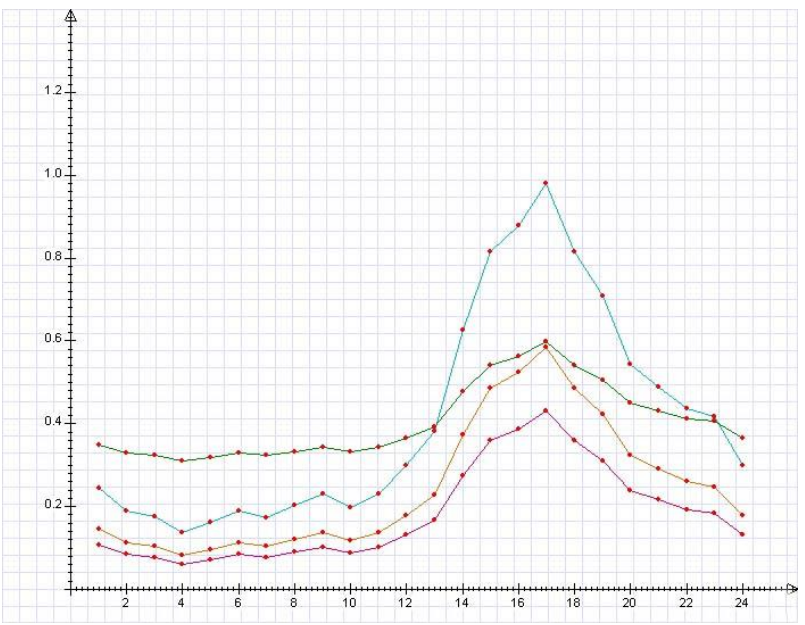

Fig. 4. "NE\&C China EPS" daily load graphs with WPP generation by 4 seasons, original variant.

In the next series of calculations, we assume that by 2035 in the NE\&C of China will be windier and the WPP generation will be more. So the WPP generation for all 4 seasons was increased up to $40 \%$, without changing the shape of these graphs, Fig. 5. 


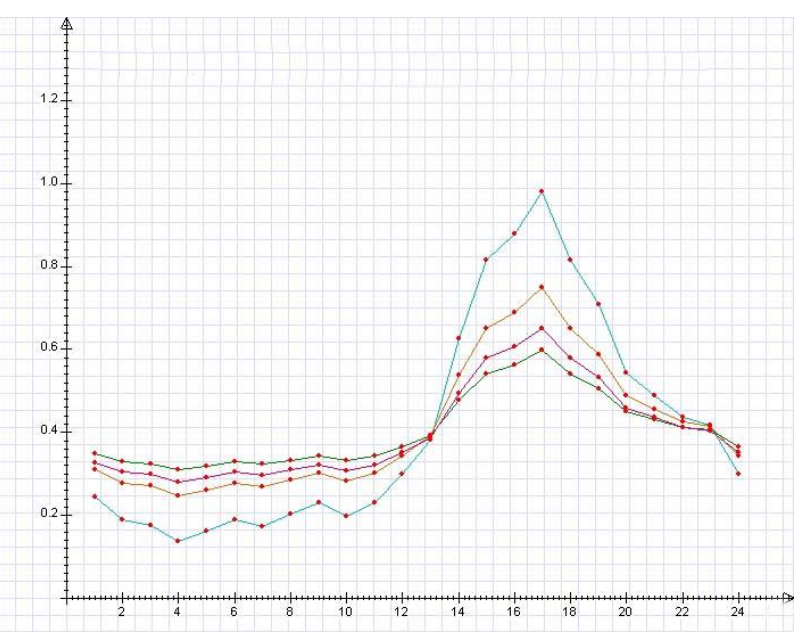

Fig. 5. "NE\&C China EPS" daily load graphs. WPP generation up to $40 \%$.

Since "NE\&C China EPS" is the largest node in the design scheme and has the largest WPP capacity, significant changes in the total costs are noticeable. However, the overall integration effect has changed insignificantly, see the Table 2. Analysis of changes in the cost structure for this variant showed that the overall reduction in costs was mainly due to decreasing the fuel component. Which is quite predictable, since the generation from non-renewable fuel power plants was supplanted by WPP.

In the next series of calculations we performed to test the impact of shape of WPP generation graphs. The WPP generation peak was changed from evening to morning, Fig. 6. Note that with these changes, the WPP generation for all 4 seasons remained the same $40 \%$. In the next variant, the WPP generation graphs were set in a stochastic manner, Fig. 7.

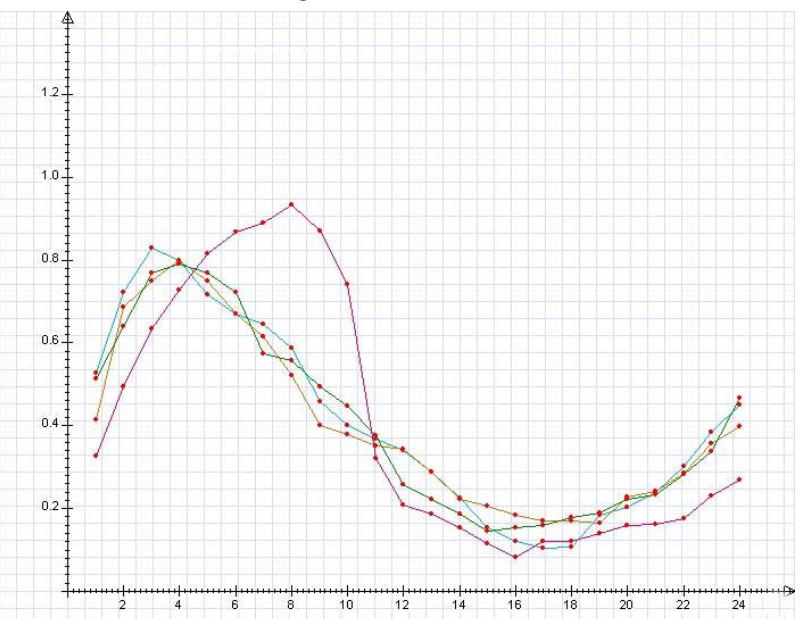

Fig. 6. "NE\&C China EPS" daily load graphs. WPP generation peak changed to the morning.

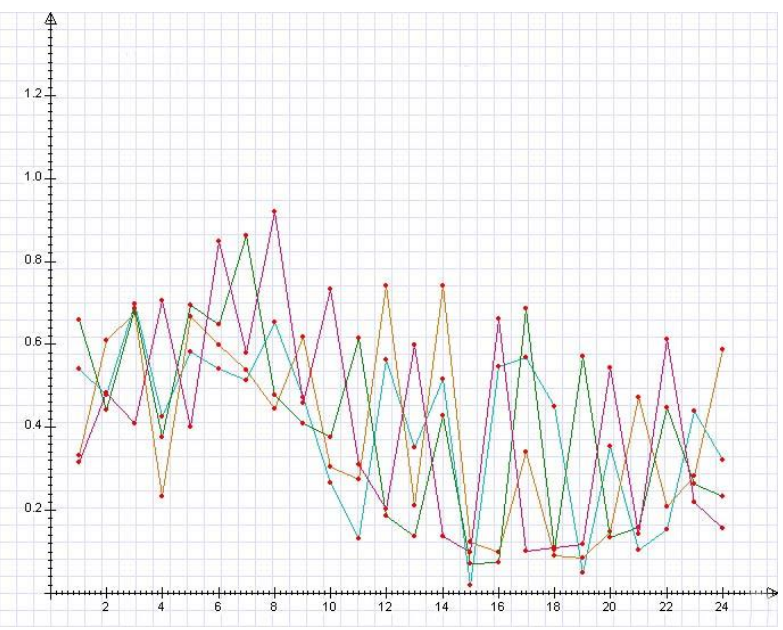

Fig. 7. "NE\&C China EPS" daily load graphs. WPP generation is set stochastically.

The calculation results for all variants are shown in table 2 .

Table 2. The total investment costs for all variants.

\begin{tabular}{|c|c|c|c|c|}
\hline \multirow{2}{*}{ Scenarios } & \multicolumn{4}{|c|}{ Total costs, billion \$ } \\
\cline { 2 - 5 } & Original & $\begin{array}{c}\text { WPP } \\
\text { gen. up } \\
\text { to 40\% }\end{array}$ & $\begin{array}{c}\text { WPP gen. } \\
\text { peak } \\
\text { changed }\end{array}$ & $\begin{array}{c}\text { WPP gen. } \\
\text { set } \\
\text { stochastic. }\end{array}$ \\
\hline $\begin{array}{c}\text { Scenario 1, } \\
\text { isolated } \\
\text { operation }\end{array}$ & 501.089 & 498.812 & 498,777 & 498,795 \\
\hline $\begin{array}{c}\text { Scenario 2, } \\
\text { interconnecte } \\
\text { d operation } \\
\text { without } \\
\text { Cenrtal Asia }\end{array}$ & 493.535 & 491.244 & 491,145 & 491,191 \\
\hline $\begin{array}{c}\text { Scenario 3, } \\
\text { Northeast } \\
\text { and Central } \\
\text { Asia } \\
\text { interconnecte } \\
\text { d operation }\end{array}$ & 492.46 & 490.175 & 490,052 & 490,096 \\
\hline
\end{tabular}

Comparing many variants, we can notice that with changing the WPP generation volumes, the values of objective function varies insignificantly - 0.1-0.2\%. Herewith, the integration effects obtained between scenarios of isolated and interconnected operation of nodes also changes insignificantly.

It can be concluded that the stochasticity of the WPP generation can only slightly affect to the total integration effects. The stochasticity of wind and solar power generation can only affects to the changing in fuel costs, due to the replacement capacities obtained by nonrenewable fuel power plants.

\section{Conclusion}

With the scenario of interconnected operation of all nodes the total investment costs are reduced. The ability to compensate for the maximum daily load due to the import from connected nodes allows reducing the added 
capacities and, as a result, the investment costs. This is one of the most important integration effects.

With changing weather conditions, for example, with an increase in windy days in a year, the WPP and SPP generation may increase (at the same time, the fuel costs from non-renewable power will decrease). But this only slightly affects the overall integration effects.

It is obvious that the share of WPP and SPP generation in the daily electrical load cannot be too large, since the risk of possible emergency situations with a shortage or overproduction of electricity in the daily balance increases. The integration of energy power systems can reduce these risks and, as a result, increase the share of WPP and SPP capacities.

This study was carried out at the Melentiev Energy Systems Institute in the framework of SB RAS Program No III. 17.6.2 (AAAA-A17-117030310447-3).

\section{References}

1. L. Belyaev, S. Podkovalnikov, V. Savelyev, L. Chudinova, The effectiveness of interstate poewr grids (Novosibirsk: Nauka, 2008) [in Russian]

2. L. Belyaev, S. Podkovalnikov, V. Savelyev, Scientific report. The program for the development of hydropower in Russia to 2030 until 2050, Irkutsk (2015) [in Russian]

3. L. Belyaev, L. Chudinova, O. Khamisov, G. Kovalev, L. Lebedeva, S. Podkovalnikov and V. Savelev, Studies of interstate electric ties in Northeast Asia, International Journal of Global Energy Issues, 17, 3 (2002) pp. 228-249

4. S. Podkovalnikov, I. Trofimov, L. Trofimov, Technological aspects of the geographic information computing system to study the interstate power grids expansion, Journal of Software Engineering, 1 (2018) pp. 349-360 [in Russian]

5. I. Trofimov, L. Trofimov, S. Podkovalnikov, Data Representation from Energy Balances by Using Geo-information System, in Vth International workshop "Critical Infrastructures: Contingency Management, Intelligent, Agent-based, Cloud Computing and Cyber Security, IWCI 2018", Advances in Intelligent Systems Research. Atlantis Press, 158 (2018) pp. 177-182

6. I. Trofimov, L. Trofimov, L. Chudinova, S. Podkovalnikov, Output Forms for Calculation Results in the Computing \& Geo-Information System, in VI-th International workshop "Critical Infrastructures: Contingency Management, Intelligent, Agent-based, Cloud Computing and Cyber Security, IWCI 2019”, Advances in Intelligent Systems Research. Atlantis Press, 169 (2019) pp. 25-29

7. S. Podkovalnikov, I. Trofimov, L. Trofimov. Data processing and optimization system to study prospective interstate power interconnections, in 10th International Conference on Asian Energy
Cooperation "AEC 2017". E3S Web Conf., 27 (2018) pp. 32-40

8. S. Podkovalnikov, I. Trofimov, L. Trofimov, L. Chudinova, The Specialized System for Processing of Interstate Power Grids Data, Energy Systems Research Journal, 1, 1 (2018) pp. 61-67

9. S.V. Podkovalnikov, V.A. Savelev, O.V. Khamisov, L.Yu. Chudinova, "Justification of Effectiveness of International Power Interconnections with Separation of Effects between Participants, Automation and remote control", vol. 10, pp. 17561765, 2018. 